\title{
Family Dysfunction and Childhood Abuse and Trauma among Offenders
}

\author{
Behanan, S. E. ${ }^{1}$, Rejani, T.G ${ }^{2}$
}

\section{ABSTRACT}

Introduction: In trying to understand the cycle between family dysfunction, childhood trauma and abuse and criminal behaviour, most studies have focused individually on different aspects of family dysfunction. Aim: To assess the family dysfunction and childhood abuse and trauma in offenders. Methodology: The research design used was cross-sectional research design. Sample size: Thirty adults with criminal back ground were selected from the prison. Purposive sampling was used for selecting the sample. Tools: Tools were used individually to assess family dysfunction, parenting styles, attachment styles and childhood abuse and trauma. The tools were Self-Report Family Inventory, Parental Authority Questionnaire, The Relationship's Questionnaire and The Childhood Traumatic Events Scale. Results: Eighty percent of offenders have undergone childhood abuse and trauma. The predominant attachment style among male offenders was found to be dismissing avoidant attachment style. The predominant attachment style among female offenders was found to be secure attachment style. Among male and female offenders, the predominant parenting style of their parents was found to be authoritative parenting style. Majority of the offenders have reported their family system as problematic. Implication: The study throws light on family dysfunction in offenders and would be beneficial in a future rehabilitation model which could include therapeutic work to resolve childhood distress and trauma.

Keywords: Family dysfunction, parenting styles, attachment styles, childhood abuse \& trauma, offenders.

There are many possible explanations of criminal behaviour which try and explain the act of crime from different perspectives. The biopsychosocial model is one such model that explains crime as resulting from an interaction between biological factors such as genetic influences and neurochemical changes, psychological such as resulting from childhood abuse and neglect and--

${ }^{1 \& 2}$ Institute of Behavioural Sciences, Gujarat Forensic Sciences University, Gujarat 


\section{Family Dysfunction and Childhood Abuse and Trauma among Offenders}

--sociological factors such as race, ethnicity and financial difficulties. The psychological factors that are involved in criminal behaviour can be summarized as different factors resulting from the family environment and childhood abuse and trauma. Families with poor communication and weak family bonds have been shown to have a correlation with children's development of aggressive/criminal behavior (Garnefski\&Okma, 1996).

Beaver (1989) explained the importance of family in his model of family functioning which consists of five dimensions. The first dimension is Family Competence dimension. This dimension relates to the structure and adaptive flexibility of the system. It consist items involving family affect, parental coalitions, problem-solving abilities, autonomy and individuality, optimistic and pessimistic views and acceptance of family members. The second dimension is of Conflict which includes items involving overt versus conflict, including arguing, blaming, fighting openly, acceptance of personal responsibility, unresolved conflict and negative tone. Another dimension is that of Cohesion. This includes items dealing with family togetherness, satisfaction received from inside the family versus outside and spending time together. The fourth dimension is that of Leadership which includes parental leadership, defectiveness and degree of rigidity of control and the last dimension is that of Emotional Expressiveness involves dealing with verbal and nonverbal expression of warmth, caring and closeness. According to Beaver(1989), the family function depends on these broad dimensions and problems in these will cause disruption in the family functioning.

Criminal behavior also has its roots in habitual deprivation of parental love and affection going back to early infancy. Inconsistent parenting, family turmoil, and multiple other stresses that flow from these disagreements compound the rejection of these children by these parents, many of whom become criminals during childhood. With all these factors working against the child's normal development, the child becomes a future criminal (Fagan, 1995).

Baumrind (1971) proposed a model for parenting in which he gave three distinct prototypes of parental authority. He proposed that permissive parents tend to make fewer demands on their children than do other parents, allowing them to regulate their own activities as much as possible. Thus, permissive parents are relatively non-controlling and tend to use a minimum of punishment with their children. Authoritarian parents tend to be highly directive with their children and value unquestioning obedience in their exercise of authority over their children. Being detached and less warm than other parents, the authoritarian parents discourage verbal give-and-take and favour punitive measures to control their children's behaviour. Authoritative parents tend to fall somewhere in between these two extremes. They are characterized as providing clear and firm direction for their children, but discipline is emphasized along with warmth, reason, flexibility and verbal give and take.

A study on criminal involvement and parenting style suggest that the permissive and neglecting/rejecting parenting styles had the most impact on the delinquent and criminal 
behavior. The authoritative parenting style had very little impact. Children exposed to neglecting/rejecting parents were at a greater risk. The authoritative type of parenting, when measured was not found to be as idyllic as expected (Spraitz, 2011).

Another indicator of future antisocial or criminal behavior is that of abuse or neglect in childhood. A statistic shows that children are at a fifty percent greater risk of engaging in criminal acts, if they were neglected or abused (Holmes et al., 2001). The "cycle of violence" is where people who grow up with abuse or antisocial behavior in the home will be much more likely to mistreat their own children, who in turn will often follow the same pattern. In a study named Understanding the Cycle, the results suggest that maltreatment greatly increases the probability of engaging in crime and that the probability increases with the experience of multiple forms of maltreatment (Currie \&Tekin, 2012).

From the above literature it can be said that family dysfunction, childhood abuse and trauma, one's parenting styles and attachment styles has an influence on the criminal behaviour. However, most of the studies done in this area have been in the western countries. Thus, it is imperative to study these factors in the Indian context.

The following research questions were developed:

1. How many offenders have undergone childhood abuse and trauma?

2. What is the predominant attachment style of the offenders?

3. What is the dominant parenting style of the parents of the offenders?

4. How many offenders have family dysfunction?

5. Is there a relationship between the attachment style of the offenders and the parenting style of their parents?

6. Is there a relationship between the parenting style of the parents of the offenders and the family dysfunction among the offenders?

\section{METHODOLOGY}

\section{Objectives:}

The following objectives were developed

1. To assess the childhood abuse and trauma among the offenders.

2. To find the predominant attachment style of the offenders.

3. To find the dominant parenting style of the parents of the offenders.

4. To assess the family dysfunction among the offenders.

5. To find the relationship between the attachment style of the offenders and the parenting style of their parents.

6. To find the relationship between parenting style of the parents of the offenders and the family dysfunction among the offenders. 


\section{Research Design:}

The research design used for the study was cross-sectional research design.

\section{Sample:}

A purposive sampling design was implemented to collect data from a sample of 30 adults with criminal background from the prison.

\section{Inclusion criteria:}

Offenders from the prison who were able to read and write and those who had spent their childhood with their parents were included in the study.

\section{Exclusion criteria:}

Offenders from the prison who were not able to read and write and those who had not spent their childhood with their parents were included in the study.

\section{Tools Used:}

The tools used for this study are the following:

\section{Childhood Traumatic Events Scale-}

This scale was developed byPennebaker(1988).This scale is a brief survey of six early traumatic experiences (death, divorce, violence, sexual abuse, illness or other) occurring before the age of 17 years and it assesses individual's understanding of their childhood trauma.

\section{The Relationships Questionnaire (Rq)-}

The Relationship Questionnaire was developed by Bartholomew(1991). It is a measure of the adult attachment style. It measures four attachment patterns- avoidant attachment pattern, anxious/ambivalent attachment pattern, secure attachment pattern and dismissing-avoidant attachment pattern.

\section{Parental Authority Questionnaire (PAQ)-}

The PAQ was developed by John R. Buri in 1971. The PAQ consists of two sets of questionnaires: one related to the mother and another related to the father. Each questionnaire consists of 30 questions each. The responses are marked on a 5-point Likert scale ranging from strongly disagree (1) to strongly disagree (5). The PAQ yields 6 separate scores and scores on each of the dimension ranges from 10 to 50. The higher the score, the greater the appraised level of the parental authority prototype measured.

The cronbach coefficient alpha values were obtained for each of the six PAQ scales: 75 for mother's permissiveness, .85 for mother's authoritarianism, .82 for mother's authoritativeness, .74 for fathers permissiveness, .87 for father's authoritarianism and .85 for father's authoritativeness. Both the test-retest reliability coefficients and the Cronbach alpha values are highly respectable.

\section{Self-Report Family Inventory-}

The Self-Report Family Inventory was developed by Beaver's and Hampson in 1990. It is 36 items, self-report instrument. It has five dimensions: health/ competence, conflict, cohesion, leadership and emotional expressiveness. The responses are measured on a Likert-type scale with 
1 being 'yes: fits our family well'; 3 being 'Some: fits our family some' and ' 5 being No: does not fit our family'.

The Self-Report Family Inventory has high internal consistency reliability with Cronbach alphas between .84 and .93 and test-retest reliabilities of .85 . It also has good validity with canonical correlations of .62 or better between the Self-report Family Inventory Competence scores and the observer-rated Beaver's Interactional Competence Scale.

\section{Statistical Analysis:}

Descriptive statistics and inferential statistics were used for the study. Percentages and correlations were calculated.

\section{Procedure:}

After getting consent from higher authorities of jail, data collection was started. The prisoners were explained the nature of the study and with their consent, the questionnaires were administered. Their doubts regarding the questionnaires were clarified during the process of administration. After obtaining the required sample, the jail authorities were thanked for their support and co-operation.

\section{RESULTS \& DISCUSSION}

\section{Childhood Abuse \& Trauma:}

The analysis of the data showed that eighty percent $(\mathrm{N}=30)$ of prisoners have undergone some form of childhood abuse and trauma. A study stated that child abuse predicted later violence after controlling for other predictors such as gender, ethnicity and age and predictability was greater for females than for males (Widom\& White, 1997). The present study also states that the percentage of childhood abuse and trauma in females is eighty six percent $(\mathrm{N}=15)$ which is higher than that of males with seventy three percent $(\mathrm{N}=15)$.

Previous studies state that maltreatment as a child greatly increases the probability of engaging in crime and that the probability increases with the experience of multiple forms of maltreatment (Currie \&Tekin, 2012). In the present study it was found that eighty one percent( $\mathrm{N}=15)$ of males had multiple forms of trauma. In exploring the different forms of maltreatment and trauma the present study found that in males, sixty seven $(\mathrm{N}=15)$ have undergone the trauma of losing a close or near one in childhood. Sixty percent $(\mathrm{N}=15)$ of males have undergone the trauma from ill health or injury in childhood. Thirty three percent $(\mathrm{N}=15)$ have undergone trauma from some major upheaval in their life in their childhood period. Thirteen percent $(\mathrm{N}=15)$ have faced trauma experienced from major fight, separation or divorce between their parents. A previous study stated that children who are separated from a biological parent are more likely to offend than children from intact families. In a study in New Zealand, Henry et al. (1996) found that boys from single-parent families were particularly likely to be convicted. This study supports the present study suggesting that role of trauma arising from parental separation is linked to crime. 


\section{Family Dysfunction and Childhood Abuse and Trauma among Offenders}

Seven percent $(\mathrm{N}=15)$ of males have undergone some sort of traumatic sexual experience and another seven percent $(\mathrm{N}=15)$ have been a victim of violence.

In females, it was found that eighty six percent $(\mathrm{N}=15)$ had undergone multiple forms of trauma. In exploring the different kinds of trauma it was found that eighty percent $(\mathrm{N}=15)$ have undergone the trauma of losing a close or near one in childhood. Forty six percent $(\mathrm{N}=15)$ of females have undergone the trauma from ill health or injury in childhood. Twenty seven percent $(\mathrm{N}=15)$ have undergone trauma from some major upheaval in their life in their childhood period. Twenty percent $(\mathrm{N}=15)$ have faced trauma experienced from major fight, separation or divorce between their parents. A previous study also supports the present study stating that parental conflict and interpersonal violence predict antisocial behaviour (Buehler et al., 1997; Kolbo et al., 1996) and thirteen percent $(\mathrm{N}=15)$ of females have undergone some sort of traumatic sexual experience and another thirteen percent $(\mathrm{N}=15)$ have been a victim of violence. The data is shown in Table 1.

\section{Attachment Style:}

Findings of a past study suggested that the exploration of past and current attachment relationships can be crucial for the understanding of violent behavior (Carlo, et al., 2014). Thus in exploring the attachment patterns among the offender the present study found that thirty three percent $(\mathrm{N}=30)$ of prisoners have got the predominant attachment styles as secure attachment style and dismissing-avoidant attachment style each. Twenty one percent $(\mathrm{N}=30)$ reported as having an avoidant attachment style and thirteen percent $(\mathrm{N}=30)$ reported as having anxious/ambivalent attachment style.

In males, forty six percent $(\mathrm{N}=15)$ have reported as having dismissing avoidant attachment style. Such people are characterized as avoiding intimacy, being highly self-reliant and independent. Twenty seven percent $(\mathrm{N}=15)$ have reported as having avoidant attachment style. Avoidant people are characterized as being afraid of intimacy, experiencing emotional highs and lows during relationships, along with much jealousy. Twenty percent $(\mathrm{N}=15)$ have reported as having a secure attachment style. People with secure attachment style have relationships which are friendly, trusting, and happy. They accept their partners regardless of faults. They tend to have long and fulfilling relationships. Seven percent $(\mathrm{N}=15)$ have reported as having anxious/ ambivalent attachment style. Such people view love in an obsessive way, with strong need for constant reciprocation and validation, along with emotional highs and lows, and feelings of jealousy and strong sexual attraction.

In females, forty seven percent $(\mathrm{N}=15)$ have reported as having secure attachment style. People with secure attachment style have relationships which are friendly, trusting, and happy. They accept their partners regardless of faults and tend have long and fulfilling relationships. Twenty percent $(\mathrm{N}=15)$ reported as having dismissing-avoidant style. Such people are characterized as avoiding intimacy, being highly self-reliant and independent. Twenty percent $(\mathrm{N}=15)$ have 


\section{Family Dysfunction and Childhood Abuse and Trauma among Offenders}

reported as having ambivalent attachment style. Such people view love in an obsessive way, with strong need for constant reciprocation and validation, along with emotional highs and lows, and feelings of jealousy and strong sexual attraction. Thirteen percent $(\mathrm{N}=15)$ reported as having avoidant attachment style. Avoidant people are characterized as being afraid of intimacy, experiencing emotional highs and lows during relationships, along with much jealousy.

The possible reason that can be attributed to the difference in the attachment styles of males and females could be the way a boy and a girl are brought up in Indian culture. The boy is always encouraged to be self-reliant and independent whereas the girl is mostly taught to be more family oriented and dependent on the family. The data is shown in Table 2.

\section{Parenting Style:}

Parenting styles were assessed on three subscales of Permissive style, Authoritarian style and Authoritative parenting style.

Among male offenders, forty one percent $(\mathrm{N}=15)$ reported that the parenting style of their parents were authoritative. Twenty six percent $(\mathrm{N}=15)$ reported that the parenting style was authoritarian. Twenty percent $(\mathrm{N}=15)$ reported mixed parenting style and thirteen percent $(\mathrm{N}=15)$ reported of their parents having a permissive style of parenting.

In males, forty one percent $(\mathrm{N}=15)$ reported that the parenting style of their mothers were authoritative. Twenty six percent $(\mathrm{N}=15)$ reported that the parenting style was authoritarian. Twenty percent $(\mathrm{N}=20)$ reported that the parenting style was permissive and thirteen percent $(\mathrm{N}=15)$ reported of their mother having a mixed style of parenting. A combination of permissive and authoritarian and permissive and authoritative was found.

In males, forty percent $(\mathrm{N}=15)$ reported that the parenting style of their fathers were authoritative. Twenty seven percent $(\mathrm{N}=15)$ reported that the parenting style was authoritarian. Six percent $(\mathrm{N}=15)$ reported that the parenting style was permissive and twenty seven percent $(\mathrm{N}=15)$ reported of their father having a mixed style of parenting. A combination of authoritarian and authoritative, permissive and authoritative and permissive and authoritarian was found. The data is shown in table 3 .

Among female offenders, sixty percent $(\mathrm{N}=15)$ reported that the parenting style of their parents were authoritative. Twenty four percent $(\mathrm{N}=15)$ reported that the parenting style was permissive. Thirteen percent $(\mathrm{N}=15)$ reported mixed parenting style and three percent $(\mathrm{N}=15)$ reported of their parents having a authoritarian style of parenting.

In females, forty seven percent $(\mathrm{N}=15)$ reported that the parenting style of their mothers were authoritative. Thirty three percent $(\mathrm{N}=15)$ reported that the parenting style was permissive. Seven percent $(\mathrm{N}=15)$ reported that the parenting style was authoritarian and thirteen percent 
$(\mathrm{N}=15)$ reported of their mother having a mixed style of parenting. A combination of permissive and authoritative was found.

In females, seventy four percent $(\mathrm{N}=15)$ reported that the parenting style of their fathers were authoritative. Thirteen percent $(\mathrm{N}=15)$ reported that the parenting style was permissive and thirteen percent $(\mathrm{N}=15)$ reported of their father having a mixed style of parenting. A combination of permissive and authoritarian was found. Among the female prisoners, no one reported as their fathers having a dominant authoritarian style parenting.

Thus, the present study reflects a hypothesis that was tested in a past study which claimed that child-rearing factors would not predict offending behavior after controlling for parental criminality. This was confirmed in a structural equation modeling analysis but not in a regression analysis (Rowe \& Farrington, 1997). The possible reason behind this is that criminal behaviour is not always shaped by parental influences. Certain traits within a structured model of personality may be linked to antisocial or criminal behaviour. The data is shown in Table 4.

\section{Family Functioning:}

Family dysfunction can be related to any form of conflict between the parents or substance use in the family or lack of defectiveness or verbal and nonverbal expression of warmth, caring and closeness in the family. Lipsey and Derzon (1998) reviewed the predictors of serious or violent offending. The moderately explanatory predictors were low parental involvement, low parental warmth, parent stress and parental discord. Thus, this result supports the present study which assessed that thirty seven percent $(\mathrm{N}=30)$ of prisoners have problems in the family competence dimension suggesting that structure and adaptive flexibility of the family system is problematic. Forty seven percent $(\mathrm{N}=30)$ show problems in the conflict dimension. Seventeen percent $(\mathrm{N}=30)$ of prisoners show difficulty in the dimension of cohesion. Forty percent $(\mathrm{N}=30)$ show problems in the domain of leadership and twenty percent $(\mathrm{N}=30)$ show difficulties in the dimension of emotional expressiveness.

In males, forty seven percent $(\mathrm{N}=15)$ show difficulty in the dimensions of Conflict and Leadership each. Thirty three percent $(\mathrm{N}=15)$ show problems in the family competence dimension and seven percent $(\mathrm{N}=15)$ show difficulty in the dimensions of Cohesion and Emotional expressiveness each.

In females, forty seven percent $(\mathrm{N}=15)$ show difficulty in the dimension of Conflict. Forty percent $(\mathrm{N}=15)$ show problems in the family competence dimension. Thirty three percent $(\mathrm{N}=15)$ show difficulty in the dimensions of Leadership and Emotional expressiveness each and twenty seven percent $(\mathrm{N}=15)$ show difficulty in the Cohesion dimension. The data is shown in Table 5. 


\section{Family Dysfunction and Childhood Abuse and Trauma among Offenders}

Correlations were used to find if a relationship between the variables that are associated with crime exists.

In male prisoners, it was found that the avoidant attachment style had a significant positive relationship with mother's authoritative parenting style $\left(\mathrm{p}=.658^{* *}\right)$ and permissive parenting style $\left(\mathrm{p}=.554^{*}\right)$. Previous study reflected that permissive parenting style predicted avoidant attachment style (Doyle et al.2003). The present study finding is also supported by another study as they concluded Indian mothers' having permissive parenting style their children prefer avoidant attachment style (Trommsdorff, G.et al.2005). The correlations are shown in the table 6. In male prisoners, the parenting style of father has shown significant negative relationship with the dimensions of leadership and conflict in family functioning. Permissive parenting style of father has shown significant negative relationship with the leadership in family functioning indicating that parental leadership, directiveness and degree of rigidity of control are compromised when the parenting style of the father is more permissive $\left(\mathrm{p}=-.529^{*}\right)$ as when there are no much rules or demands at home then the directiveness in the family is compromised with. The authoritative parenting style has shown significant negative relationship with the level of conflict in the family ( $\left.\mathrm{p}=-537^{*}\right)$. Authoritative parenting that is characterized as providing clear and firm direction for their children and discipline is emphasized along with warmth, reason, flexibility and verbal give and take will cause lesser number of conflicts as home as the boundaries are clearly defined with warmth and empathy. This data is shown in table 7.

In female prisoners, the parenting style of the mother has shown significant negative relationship with the level of family functioning. The authoritative parenting style of the mother has shown significant negative relationship with the level of conflict in one's family $\left(\mathrm{p}=-.771^{* *}\right)$. This indicated that more is the parenting style of the mother is authoritative in nature the lesser will be the conflicts in the family.

\section{CONCLUSIONS}

1. Eighty percent of offenders have undergone childhood abuse and trauma.

2. The predominant attachment style among male offenders was found to be dismissing avoidant attachment style.

3. The predominant attachment style among female offenders was found to be secure attachment style.

4. Among male and female offenders, the predominant parenting style of their parents was found to be authoritative parenting style.

5. Majority of the offenders have reported their family system as problematic.

\section{IMPLICATIONS}

As it is clear from the study that childhood trauma and family conflicts are found in high rates among offenders, this could point us to a new direction making it important to look into these aspects while dealing with such a population and using these indicators in prevention. Such 
details regarding the emotional and psychological trauma in them could provide helpful in formulating a therapeutic intervention model aiming at those aspects thus helping in the rehabilitation process.

\section{FUTURE DIRECTION}

Future in depth studies can be done by taking a larger sample. A comparative study with nonoffenders can also be done in the future.

\section{Table 1}

Percentage of Childhood Abuse and Trauma among Offenders

\begin{tabular}{|l|l|l|}
\hline Kinds of Trauma & Males & Females \\
\hline Death of a close one & $67 \%$ & $80 \%$ \\
\hline $\begin{array}{l}\text { Facing Divorce of separation } \\
\text { between parents }\end{array}$ & $13 \%$ & $20 \%$ \\
\hline Physical Violence & $7 \%$ & $13 \%$ \\
\hline Sexual abuse & $7 \%$ & $13 \%$ \\
\hline Trauma from major illness & $60 \%$ & $46 \%$ \\
\hline $\begin{array}{l}\text { Significant major upheaval in } \\
\text { life }\end{array}$ & $33 \%$ & $27 \%$ \\
\hline
\end{tabular}

\section{Table 2}

Percentage of Attachment Styles among Offenders

\begin{tabular}{|l|l|l|l|}
\hline Attachment Styles & Males & Females & $\begin{array}{l}\text { Offenders (Males } \\
\text { and Females) }\end{array}$ \\
\hline Dismissing-avoidant & $46 \%$ & $20 \%$ & $33 \%$ \\
\hline Avoidant & $27 \%$ & $13 \%$ & $21 \%$ \\
\hline Ambivalent-anxious & $7 \%$ & $20 \%$ & $13 \%$ \\
\hline Secure & $20 \%$ & $47 \%$ & $33 \%$ \\
\hline
\end{tabular}

Table 3

Parenting Style of Parents of Male Offenders

\begin{tabular}{|l|l|l|l|}
\hline Parenting Style & Mother & Father & Both Parents \\
\hline Authoritative & $41 \%$ & $40 \%$ & $41 \%$ \\
\hline Authoritarian & $26 \%$ & $27 \%$ & $26 \%$ \\
\hline Permissive & $20 \%$ & $6 \%$ & $13 \%$ \\
\hline Mixed Parenting & $13 \%$ & $27 \%$ & $20 \%$ \\
\hline
\end{tabular}

\section{Table 4}

Parenting Style of Parents of Female Offenders

\begin{tabular}{|l|l|l|l|}
\hline Parenting Style & Mother & Father & Both Parents \\
\hline Authoritative & $47 \%$ & $74 \%$ & $60 \%$ \\
\hline Authoritarian & $7 \%$ & 0 & $3 \%$ \\
\hline Permissive & $33 \%$ & $13 \%$ & $24 \%$ \\
\hline Mixed Parenting & $13 \%$ & $13 \%$ & $13 \%$ \\
\hline
\end{tabular}


Table 5

Family Dysfunction among Offenders

\begin{tabular}{|l|l|l|l|}
\hline $\begin{array}{l}\text { Domains Of Family } \\
\text { Function }\end{array}$ & Males & Females & Offenders \\
\hline Family Competence & $33 \%$ & $40 \%$ & $37 \%$ \\
\hline Conflict & $47 \%$ & $47 \%$ & $47 \%$ \\
\hline Cohesion & $7 \%$ & $27 \%$ & $17 \%$ \\
\hline Leadership & $47 \%$ & $33 \%$ & $40 \%$ \\
\hline $\begin{array}{l}\text { Emotional } \\
\text { Expressiveness }\end{array}$ & $7 \%$ & $33 \%$ & $20 \%$ \\
\hline
\end{tabular}

Table 6

Relationship between Attachment style of Male Offenders and their Mother's Parenting Style

\begin{tabular}{|c|l|l|}
\hline $\begin{array}{l}\text { ATTACHMENT STYLE } \\
\text { OF MALE PRISONERS }\end{array}$ & $\begin{array}{l}\text { PARENTING STYLE OF } \\
\text { MOTHER }\end{array}$ & PALUE \\
\hline AVOIDANT & PERMISSIVE & $.554^{*}$ \\
\cline { 2 - 3 } & AUTHORITATIVE & $.658^{*}$ \\
\hline
\end{tabular}

$*$ =significant at .05 level $* *=$ significant at .01 level

Table 7

Relationship between the Family Functioning of Males Offenders and their Father's Parenting Style

\begin{tabular}{|l|l|l|}
\hline $\begin{array}{l}\text { FAMILY FUNCTIONING } \\
\text { OF MALE PRISONERS }\end{array}$ & $\begin{array}{l}\text { FATHER PARENTING } \\
\text { STYLE OF MALUE } \\
\text { PRISONERS }\end{array}$ & P VALE \\
\hline LEADERSHIP & PERMISSIVE & $-.529^{*}$ \\
\hline CONFLICT & AUTHORITATIVE & $-.537^{*}$ \\
\hline
\end{tabular}

$*=$ significant at .05 level

Table 8

Relationship between the Family Functioning of Female Prisoners and their Mother's Parenting Style

\begin{tabular}{|l|l|l|}
\hline $\begin{array}{l}\text { FAMILY FUNCTIONING } \\
\text { OF FEMALE PRISONERS }\end{array}$ & $\begin{array}{l}\text { MOTHER PARENTING } \\
\text { STYLE OF FEMALE } \\
\text { PRISONERS }\end{array}$ & PALUE \\
\hline CONFLICT & AUTHORITATIVE & $-.771^{* *}$ \\
\hline
\end{tabular}

$* *=$ significant at .01 level. 
REFERENCES

Baumrind, D. (1971). Current Patterns of parental authority.Developmental Psychology Monographs, 4 (2, Pt. 2).

Beavers, W.R. (1989).The Beavers Systems Model of Family Assessment. In C.N. Ramsey (ed.). Family Systems in Medicine. New York: Guildford Press.

Beuhler, C., Anthony, C., Krishnakumar, A., Stone, G., Gerard, J., \& Pemberton, S. (1997). Interparental conflict and youth problem behaviours: A meta-analysis. Journal of Child and Family Studies, 6, 233-247.

Causes of Crime - Explaining Crime, Physical Abnormalities, Psychological Disorders, Social And Economic Factors, Broken Windows, Income And Education. Retrieved from: http://law.jrank.org/pages/12004/Causes-Crime.html.on 1.1.2015.

Currie, J., \&Tekin, E. (2012).Understanding the Cycle: Childhood Maltreatment and Future Crime. Journal of Human Resources, 42, 509-549.

Garnefski, N., \&Okma, S. (1996). Addiction-risk and aggressive/criminal behavior in adolescence: Influence of family, school, and peers. Journal of Adolescence, 19, 503-512.

Henry, B., Caspi, A., Moffitt, T.E., \& Silva, P. (1996). Temperamental and familial predictors of violent and nonviolent criminal convictions: Age 3 to age 18. Developmental Psychology, 32, 614-623.

Holmes, S. E., Slaughter, J. R., \&Kashani, J. (2001). Risk factors in childhood that lead to the development of conduct disorder and antisocial personality disorder. Child Psychiatry and Human Development, 31, 183-193.

Kolbo, J.R., Blakely, E.H., \&Engleman, D. (1996). Children who witness domestic violence: A review of empirical literature. Journal of Interpersonal Violence, 11, 281-293.

Lipsey, M.W. \&Derzon, J. H. (1998). Predictors of violent or serious delinquency in adolescence and early adulthood: A synthesis of longitudinal research. In R. Loeber\& D.P. Farrington (Eds.), Serious and violent juvenile offenders: Risk factors and successful interventions. Mahwah, NJ: Lawrence Erlbaum.

Rowe, D.C., \& Farrington, D.P. (1997).The familial transmission of criminal convictions.Criminology, 35, 177-201.

Schimmenti, A., Passanisi, A., Pace, U., Manzella, S., Carlo, G.G., \&Caretti, V. (2014). The Relationship between Attachment and Psychopathy: The Relationship between Attachment and Psychopathy: A Study with a Sample of Violent Offenders. Current Psychology, 33 (3): 256-270.

Spraitz, J. D. (2011). Parenting Styles and Criminal Involvement: A Test of Baumrind'sTypology.Indiana University of Pennsylvania.

The Real Root Causes of Violent Crime: The Breakdown of Marriage, Family, and Community.Patrick F. Fagan, Ph.D. March 17, 1995. The Heritage Foundation.

Trommsdorff, G., R. Mishra, B. Mayer, I. Albert and B. Schwarz. (2005). The value of children in urban and rural India: Cultural background and empirical results. The value of children in cross-cultural perspective. Case studies from eight societies Lengerich: Pabst Science.

Widom, C.S., \& White, H.R. (1997). Problem behaviours in abused and neglected children grown up: Prevalence and co-occurrence of substance use, crime and violence. Criminal Behaviour and Mental Health, 7, 287-310. 